Research Paper

\title{
Backward automatic calibration for three-dimensional landslide models
}

\author{
Giacomo Titti $^{\mathrm{a}, \mathrm{b}}$, Giulia Bossi ${ }^{\mathrm{b}, *}$, Gordon G.D. Zhou ${ }^{\mathrm{c}}$, Gianluca Marcato ${ }^{\mathrm{b}}$, Alessandro Pasuto ${ }^{\mathrm{b}}$ \\ a DICAM-UNIBO, Department of Civil, Chemical, Environmental and Materials Engineering, Alma Mater Studiorum University of Bologna, Viale Risorgimento 2, Bologna, \\ 40136, Italy \\ b IRPI-CNR, Research Institute for Geo-Hydrological Protection, National Research Council, C.so Stati Uniti, 4, Padova, 35127, Italy \\ ${ }^{\mathrm{c}}$ IMHE-CAS, Key Laboratory of Mountain Hazards and Earth Surface Process/Institute of Mountain Hazards and Environment, Chinese Academy of Sciences, Block 4, \\ Renminnanlu Road, Chengdu 610041, China
}

\section{A R T I C L E I N F O}

Handling Editor: Biswajeet Pradhan

\section{Keywords:}

Automatic landslide modelling

FLAC3D $^{\text {TM }}$

Back-analysis

Optimization

Decision Support System

\begin{abstract}
A B S T R A C T
Back-analysis is broadly used for approaching geotechnical problems when monitoring data are available and information about the soils properties is of poor quality. For landslide stability assessment back-analysis calibration is usually carried out by time consuming trial-and-error procedure. This paper presents a new automatic Decision Support System that supports the selection of the soil parameters for three-dimensional models of landslides based on monitoring data. The method considering a pool of possible solutions, generated through permutation of soil parameters, selects the best ten configurations that are more congruent with the measured displacements. This reduces the operator biases while on the other hand allows the operator to control each step of the computation. The final selection of the preferred solution among the ten best-fitting solutions is carried out by an operator. The operator control is necessary as he may include in the final decision process all the qualitative elements that cannot be included in a qualitative analysis but nevertheless characterize a landslide dynamic as a whole epistemological subject, for example on the base of geomorphological evidence. A landslide located in Northeast Italy has been selected as example for showing the system potentiality. The proposed method is straightforward, scalable and robust and could be useful for researchers and practitioners.
\end{abstract}

\section{Introduction}

Back-analysis (or backward analysis) is a technique broadly used for dealing with geotechnical problems (Gioda and Sakurai, 1987; Swoboda et al., 1999) despite its well-known limitations (Leroueil and Tavenas, 1981; Deschamps and Yankey, 2006). For landslide modelling, back-analysis is often used to determine the soil parameters for the numerical model to eventually be used in designing of structural countermeasures. As a matter of fact the results of geotechnical laboratory test performed on landslide soils frequently do not provide sound information about the actual mechanical strength of the in situ material (Suits et al., 2008) due to scale effects (Mitchell, 1991), sample disturbance (Tang et al., 1999) and shear strength recovery effects (Stark and Hussain, 2010). Back-analysis, as an empirical method, cuts off all the uncertainties related to the limited information of the soil characteristics relying on direct measures provided by a monitoring system deployed on site (Peck, 1969).
However back-analysis of landslide stability based on monitoring data is generally strongly operator-dependent and the selection of the parameters is performed through a time-consuming trail-and-error procedure (Borgatti et al., 2008; Marcato et al., 2012). Several methods already propose to automatize (or partially automatize) the selection of the optimal soil parameters combination (Doherty and Lehane, 2009; Zhang et al., 2010; Schädler et al., 2015; Sun et al., 2016; Yin et al., 2018) but none propose a Decision Support System (DSS) that could permit to the operator to check each step of the process and integrate also the operator heuristic.

This paper presents a semi-automatic system based on finite difference three-dimensional models of landslides for the selection of the optimal geotechnical parameters combination. It has been applied in supporting decision making process according to the Multiattribute Utility Theory (Olson, 2008) face with a multi-objective non-linear optimization problem (Deb, 2005). The possibility to rely on an operator-independent procedure increases the reliability of the analysis,

* Corresponding author.

E-mail addresses: giacomo.titti@irpi.cnr.it (G. Titti), giulia.bossi@irpi.cnr.it (G. Bossi), gordon@imde.ac.cn (G.G.D. Zhou), gianluca.marcato@irpi.cnr.it (G. Marcato), alessandro.pasuto@irpi.cnr.it (A. Pasuto).

Peer-review under responsibility of China University of Geosciences (Beijing).

https://doi.org/10.1016/j.gsf.2020.03.011

Received 29 July 2019; Received in revised form 15 January 2020; Accepted 16 March 2020

Available online $\mathrm{xxxx}$

1674-9871/@ 2020 China University of Geosciences (Beijing) and Peking University. Production and hosting by Elsevier B.V. This is an open access article under the CC BY-NC-ND license (http://creativecommons.org/icenses/(1y-nc-nd/4.0/). 
and thus, for example, of the structural countermeasure designed and based on that model, by removing the inevitable biases of the human operator. This, however, does not mean that a human control on these systems is not necessary. On the contrary it is still necessary to discriminate between a selection of the best fitting solutions performed by the DSS, considering the displacement pattern of the landslide in areas where no measures are available but where other qualitative information such as geomorphological evidence may be present, increasing the overall reliability of the method.

The DSS is based on a backward analysis of the superficial and deep monitored displacements of the slope instability. Therefore the system works in 3 steps: (1) the construction of the admissible numerical solutions through the generation of multiple numerical simulations of the displacement pattern of the landslide; (2) the proximity evaluation of the surveyed and the simulated displacement; (3) the selection of the most suitable solution in parameters combination. The results have been also compared with the parameters combination selected by an operator through trial-and-error procedure in order to estimate the uncertainties introduced by the operator biases.

\section{Materials and methods}

For landslide modelling, the main sources of uncertainty associated with back-analysis are: \#1 the reconstruction of the actual slip surface (SS) (if any) along the whole slope, \#2 the definition of the pore pressure distribution along the slope, \#3 the presence of three dimensional effects, \#4 the actual strength of materials in heterogeneous slope profiles (Deschamps and Yankey, 2006; Hasan and Najjar, 2013).

The research has been focused on the analysis of the influence of soil parameters (\#4) by the three-dimensional model reconstruction of the slope instability from a group of admissible numerical solutions. The three dimensional effect (\#3) has been, therefore, considered substantially overcame by the use of a three-dimensional model.

The main aim of the multi-objective optimization process is to minimize the objective functions affected by unknown variables and restricted by a set of constraints (Said et al., 2014).

The optimization problem engaged can be theorized, at the same time, as a standard optimization paradigm and a heuristic optimization paradigm (Winker and Gilli, 2004). In modelling optimization, they are distinguishable according to the approach to the paradigm. In this work, the optimization problem has been tackled as a standard optimization paradigm which can be mathematically expressed as:

$\max f(x)$

where $x \in X$ and $X$ is a subset of $\mathrm{n}$-dimensional vector space (Winker and Gilli, 2004) and $f(x)$ is the objective function (Meier et al., 2009). The paradigm presumes the existence of a unique solution reached by a simple enumeration or differential calculus. Therefore, to reduce the complexity of the optimization problem and find a solution, the multi-objective optimization problem has been solved as a single-objective optimization problem aimed to optimize singularly two consequential objective functions.

The standard optimization paradigm has been, thus, approached in back-analysis through a global and direct search method. The feature "global" highlights the existence of optimal design parameters obtained from the absolute minimization of the objective function (Stuckman et al., 1991). Indeed, "direct search" describes the iterative use of trial values in a comparison-based analysis between monitored and calculated variables until their divergence is minimized (Swoboda et al., 1999; Lewis et al., 2000). In a general application, the trial values in back-analysis optimization, applied to slope stability, is represented by the set of unknown soil parameters provided by a search algorithm. Taking a set of them $\left(S_{t}\right)$, the $t$-th solution is modelled and the relative objective function is evaluated over the iterations until the optimization paradigm will be satisfied. The iterative calculation $(t-t h)$ is fed by the set of trial values of the unknown soil parameters which characterize the single solution modelled. They are calculated as:

$S_{t+1}=S_{t}+\lambda_{t} d_{t}$

where $\lambda_{t}$ and $d_{t}$ are respectively the entity and the search direction of the step set, both depending on the assumed optimization technique (Jeon and Yang, 2004). In this work the DSS is based on a pool of modelled solutions preliminary determined which allows the visualization of the solutions cloud and their behavior. Thus, $\lambda$ and $d$ values have been established a priori in order to satisfy all the soil parameters permutation assumed without any specific optimization technique.

The system proposed requires at least 3 superficial displacements $\left(\mathbb{R}^{3}=\left\{\left(v_{1}, v_{2}, v_{3}\right) \mid v \in \mathbb{R}\right\}\right.$ with $\left.\vec{V}_{m}=\left(v_{m_{1}}, v_{m_{2}}, v_{m_{3}}\right) \in \mathbb{R}^{3}\right)$ and 3 deep displacements $\left(\mathbb{R}^{2}=\left\{\left(v_{1}, v_{2}\right) \mid v \in \mathbb{R}\right\}\right.$ with $\left.\vec{V}_{S S m}=\left(v_{S S m_{1}}, v_{S S m_{2}}\right) \in \mathbb{R}^{2}\right)$ surveyed by the monitoring equipment which is, therefore, composed by $n$ superficial benchmarks and $k$ deep monitoring points $(n=3$ and $k=3$ are the minimum requirements).

The numerical three-dimensional model that better reproduces the monitored displacements assigns the characteristic parameters to the landslide material. Then, the fitness criteria for the solution selection is based on the minimization of the function (Opt) which evaluates the proximity of the numerical three-dimensional models with the monitored slope failure. It can be expressed as:

$O p t=f\left(\alpha_{m}, \alpha_{S S m}, \gamma_{m}, r_{m}, \alpha, \alpha_{S S}, \gamma, r\right)$

The variables are described in Table 1.

The pool of admissible solutions is automatically computed in FLAC3D ${ }^{\mathrm{TM}}$ which allows the calculation of all the numerical models with permuted soil parameters. FLAC3D ${ }^{\mathrm{TM}}$ (Fast Lagrangian Analysis of Continua) uses explicit algorithm to describe the evolutionary behavior of the displacements (Li et al., 2006).

FLAC3D ${ }^{\mathrm{TM}}$ has been selected to automatize the generation of the pool of the modelled solutions considering different permutation of soil parameters. Generally, only a part of the total soil parameters combinations reach convergence and may be used for the following analysis, the rest may generate excessive displacements that are not manageable numerically by FLAC3D ${ }^{\mathrm{TM}}$.

Table 1

Landslide parameters for movement description.

\begin{tabular}{|c|c|c|c|c|}
\hline & Definition & Variable & Dimension & $\begin{array}{l}\text { Unit of } \\
\text { measure }\end{array}$ \\
\hline \multirow[t]{5}{*}{ Monitored } & $\begin{array}{l}\text { Direction of the horizontal } \\
\text { component of the } \\
\text { displacement }\end{array}$ & $\alpha_{m}$ & - & $\operatorname{rad}$ \\
\hline & $\begin{array}{l}\text { Direction of the horizontal } \\
\text { component of the } \\
\text { displacement at SS }\end{array}$ & $\alpha_{S S m}$ & - & $\mathrm{rad}$ \\
\hline & $\begin{array}{l}\text { Direction of the vertical } \\
\text { component of the } \\
\text { displacement }\end{array}$ & $\gamma_{m}$ & - & $\operatorname{rad}$ \\
\hline & Displacement intensity & $I_{m}$ & $\mathrm{~L}$ & - \\
\hline & $\begin{array}{l}\text { Mutual ratio of displacement } \\
\text { intensities }\end{array}$ & $r_{m}$ & $L / L$ & - \\
\hline \multirow[t]{5}{*}{ Modelled } & $\begin{array}{l}\text { Direction of the horizontal } \\
\text { component of the } \\
\text { displacement }\end{array}$ & $\alpha$ & - & $\operatorname{rad}$ \\
\hline & $\begin{array}{l}\text { Direction of the horizontal } \\
\text { component of the } \\
\text { displacement at SS }\end{array}$ & $\alpha_{S S}$ & - & $\operatorname{rad}$ \\
\hline & $\begin{array}{l}\text { Direction of the vertical } \\
\text { component of the } \\
\text { displacement }\end{array}$ & $\gamma$ & - & $\operatorname{rad}$ \\
\hline & Displacement intensity & $I$ & $\mathrm{~L}$ & - \\
\hline & $\begin{array}{l}\text { Mutual ratio of displacement } \\
\text { intensities }\end{array}$ & $r$ & $L / L$ & - \\
\hline
\end{tabular}


The movement of the landslide in this analysis are described by: the displacement along the slip surface which are monitored by inclinometers and the displacement at the surface which are monitored by GNSS benchmarks. Thus, 4 soil parameters have been associated to each numerical solution: the cohesion $\left(c_{S S}\right)$ and friction angle $\left(\varphi_{S S}\right)$ of the landslide material close to the slip surface, the cohesion (c) and friction angle $(\varphi)$ of the landslide surface material. The numerical model provides the displacements of the cells vertices $\left(\mathbb{R}^{3}=\left\{\left(v_{1}, v_{2}, v_{3}\right) \mid v \in \mathbb{R}\right\}\right.$ with $\left.\vec{V}=\left(v_{1}, v_{2}, v_{3}\right) \in \mathbb{R}^{3}\right)$.
The model is based on the evaluation of the similarity in displacement directions and intensity of monitored and simulated points. A scheme of the DSS is shown in Fig. 1 The monitored points are spatially coupled with the geometrical centroids of the relative cells and the surveyed displacements are compared with the weighted average of the vertices displacement $\left(\alpha, \alpha_{S S}, \gamma, I\right)$ calculated by the numerical model. The evidence of each cell vertex $(j=1, \ldots, 8)$ depends on the relative intensity of the displacement.

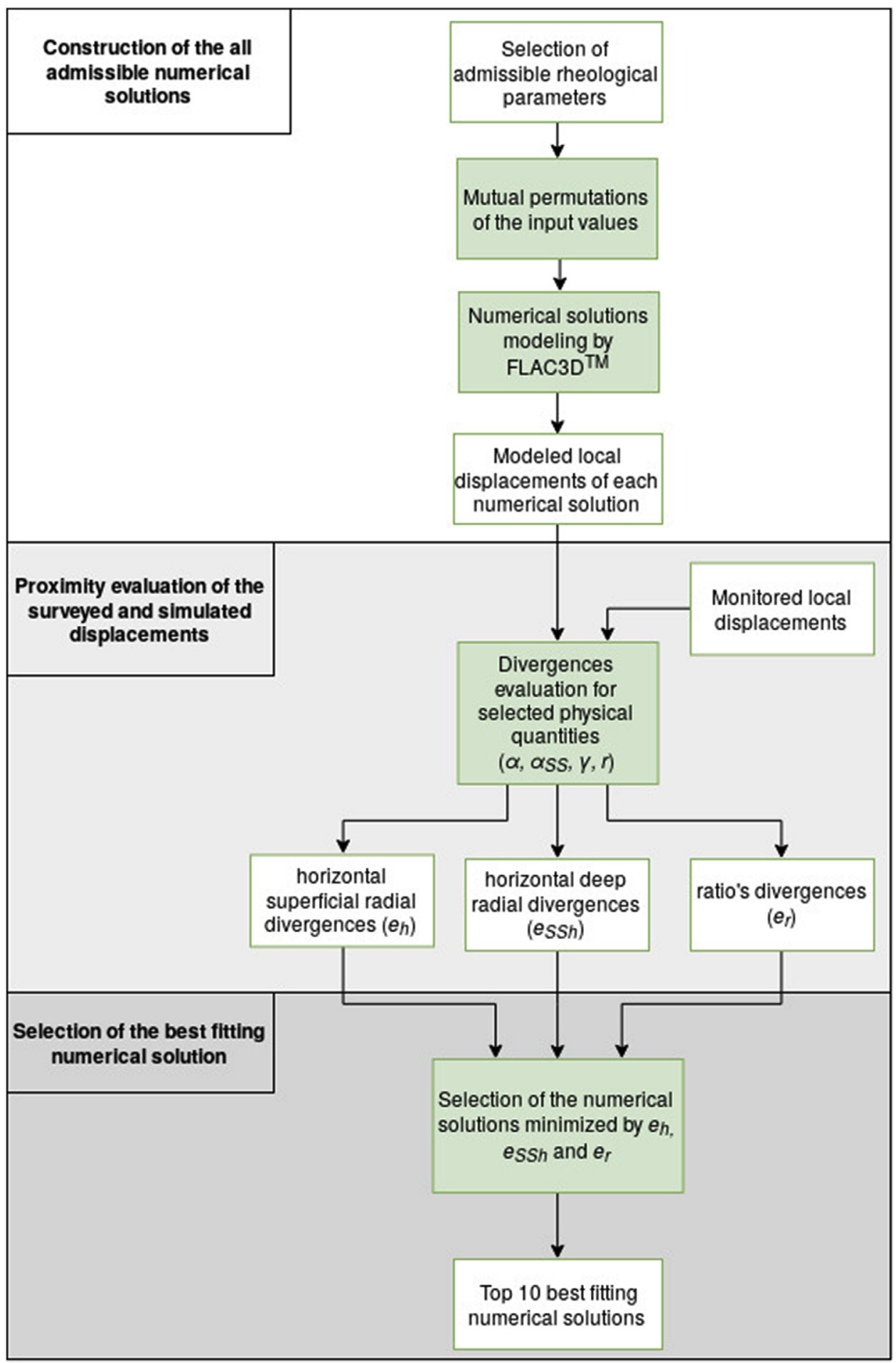

Fig. 1. Flow-chart of the DSS implemented. 


$$
\left\{\begin{array}{cc}
\bar{\alpha}_{i}=\left(\frac{\sum_{j=1}^{8} \alpha_{j} \cdot\left|\vec{V}_{j}\right|}{\sum_{j=1}^{8}|| \vec{V}_{j}||}\right)_{i} & i=1, \ldots, n \\
\bar{\alpha}_{S S_{l}}=\left(\frac{\sum_{j=1}^{8} \alpha_{S S j} \cdot\left|\vec{V}_{j}\right|}{\sum_{j=1}^{8}|| \vec{V}_{j}||}\right)_{l} & l=1, \ldots, k \\
\bar{\gamma}_{i}=\left(\frac{\sum_{j=1}^{8} \gamma_{j} \cdot \| \vec{V}_{j}||}{\sum_{j=1}^{8}|| \vec{V}_{j}||}\right)_{i} & i=1, \ldots, n \\
\bar{I}_{i, z}=\left(\frac{\sum_{j=1}^{8}|| \vec{V}_{j} \|}{8}\right)_{i} & i=1, \ldots, n
\end{array}\right\}
$$

$\bar{r}_{i, z}=\frac{\bar{I}_{i}}{\bar{I}_{z}} i, z=1, \ldots, n$

Overall, the movement of the soil mass is parameterized by: the horizontal displacement directions of the superficial and deep reference points; the vertical displacement directions of the superficial reference points; and additionally the mutual ratios between the entities of the superficial displacements.

From the numerical point of view, the simulated displacement of the deep layer is significantly reduced by the contact cells face displacement inducing the error in the entity evaluation. Therefore, the calculation of the cell displacement, like the weighted average of the vertices displacement entity, has been proposed. In this manner, it is possible to create the relational function between the punctual vertex and the volume of the cell.

Among the entire variable used, $r$ is probably the most important in volumetric terms. It creates dependencies between the superficial monitoring points and describes the relations between the displacement entities of the superficial monitoring points, pointing out the shape of the deformation. The ratios $r$ are not considered for the deep monitored point because of the small entity of the displacements, which are excessively affected by measurement errors. The results related to these physical quantities may be affected by higher errors than the errors associated to the omission of $r_{S S}$ visible in Eq. (4) and Eq. (5).

The quality of each solution is evaluated by the directional divergences and the intensities relationship of the displacement. The former is calculated as differences between monitored and calculated horizontal angles and vertical angles, while the latter as ratios of intensity displacements for each spatial coupled point. Thus, at least 9 radial divergences (6 horizontal and 3 vertical) of 6 points of relevance and 6 divergences between the ratios of 3 superficial points of relevance are considered from any numerical solution. Overall, 15 parameters should be minimized to select the most convergence numerical solution to the monitored case study.

Any divergence class selected represents a physical quantity that characterizes the landslide movement. In order to associate a singular numerical value to each physical phenomenon, the arithmetic averages of: the horizontal superficial radial divergences $\left(e_{h}\right)$; the horizontal deep radial divergences $\left(e_{S S h}\right)$; the vertical superficial radial divergences $\left(e_{v}\right)$ and the ratio divergences $\left(e_{r}\right)$ are normalized and calculated (Table 2) by the following equations:

$$
\left\{\begin{aligned}
e_{h} & =\sum_{i=1}^{n} \frac{\left|\alpha_{m_{i}}-\bar{\alpha}_{i}\right|}{2 \pi \cdot n} \quad i=1, \ldots, n \\
e_{S S h} & =\sum_{l=1}^{k} \frac{\left|\alpha_{S S m_{l}}-\bar{\alpha}_{S S_{l}}\right|}{2 \pi \cdot k} \quad l=1, \ldots, k \\
e_{v} & =\sum_{i=1}^{n} \frac{\left|\gamma_{m_{i}}-\bar{\gamma}_{i}\right|}{2 \pi \cdot n} \quad i=1, \ldots, n \\
e_{r} & =\sum_{i=1}^{n} \frac{\left|r_{m_{i}}-\bar{r}_{i}\right|}{n^{2}} \quad i=1, \ldots, n
\end{aligned}\right.
$$

To compare the proximal displacement of the slip surface and the superficial displacements, the $\gamma$ variable can be neglected and thus all the derivative variables, which describe the vertical displacements, are neglected.

The near-optimal solution of the multi-objective optimization problem is reached facing the problem as single-objective. It is based on a consequential resolution of two single-objective functions. The first function selects the domain of the second (Fig. 2). The objective functions of the double standard optimization paradigm are expressed as:

$\operatorname{Opt}_{\alpha}\left(\alpha_{m}, \alpha_{S S m}, \alpha, \alpha_{S S}\right)=\frac{e_{h}+e_{S S h}}{2}$

$O p t_{r}\left(r_{m}, r\right)=e_{r}$

At first, the minimization of Eq. (7) defines the numerical solutions (S) that compose the $\operatorname{Dom}\left(\mathrm{Opt}_{\mathrm{r}}\right)$.

$\operatorname{Dom}\left(O p t_{r}\right)=\left\{e_{r} \in \mathbb{R}: e_{r}=e_{r}\left(S\left(O p t_{\alpha_{1}}\right)\right), \ldots, e_{r}\left(S\left(O p t_{\alpha_{w}}\right)\right)\right\}$

The numerosity of the domain is defined by the first quartile of the ascending ordered $O p t_{\alpha}$ values. $w$ is the number of the solutions populating the first quartile.

The solution of the optimization problem is reached at the second stage by the direct search of the absolute minimum of Eq. (8).

The variables selected $\left(\alpha, \alpha_{S S}, r\right)$ characterize the dynamic displacements of the landslide. The most intuitive are the angles $\alpha$ and $\alpha_{S S}$. The first describes the spatial direction of the superficial displacement and the second the horizontal direction of the displacement of the deep cells layer in contrast with the stable soil.

The behavior of the deep soil elements of a landslide is influenced by its interaction with the stable soil through the slip surface, which induces a localized deviation in the inclinometers vertical profiles. In this manner, the discontinuity surface between the moving press and the stable ones can be traced.

\section{Case study}

The landslide data used to test the method come from long investigated heart shaped slope instability phenomenon in Northeast Italy $\left(46^{\circ} 23^{\prime} 49^{\prime \prime} \mathrm{N}, 12^{\circ} 42^{\prime} 51^{\prime \prime} \mathrm{E}\right)$ that interferes with the National Road (Fig. 3). The phenomenon consists of two adjacent landslides with distinct crowns but converging toes. The complex topography and the mutually dependent kinematic of the two landslides requires to implement a threedimensional model to adequately reconstruct the displacement pattern (Sinigardi et al., 2015).

The material constituting the landslide are well-graded colluviums, in average somewhat coarser in the western landslide (called "Frana 2") and with more fine fraction in the eastern landslide (called "Frana 1"). The particle size distribution of Frana 1 shows a material that is a Wide-Grade Loose Soils (WGLS) (Cui et al., 2019) composed by 15\% gravel, $45 \%$ sand, $30 \%$ silt and $10 \%$ clay. The PI of the fine material is around 10 in very much all the samples analyzed at different depths.

No direct geotechnical mechanism for explaining the movement of the landslide has been identified, we are just observing a physical phenomenon (movement from monitoring data) and trying to reproduce its behavior. However, rainfall infiltration has been excluded as direct triggering factor for this landslide. There are several evidences supporting this statement: a little correlation between displacements measured

Table 2

Optimization based variables.

\begin{tabular}{ll}
\hline Variable & Definition \\
\hline$e_{h}$ & arithmetic average of the horizontal superficial radial divergences $(\alpha)$ \\
$e_{s s h}$ & arithmetic average of the horizontal deep radial divergences $\left(\alpha_{S S}\right)$ \\
$e_{v}$ & arithmetic average of the vertical superficial radial divergences $(\gamma)$ \\
$e_{r}$ & arithmetic average of the ratio divergences $(r)$ \\
\hline
\end{tabular}




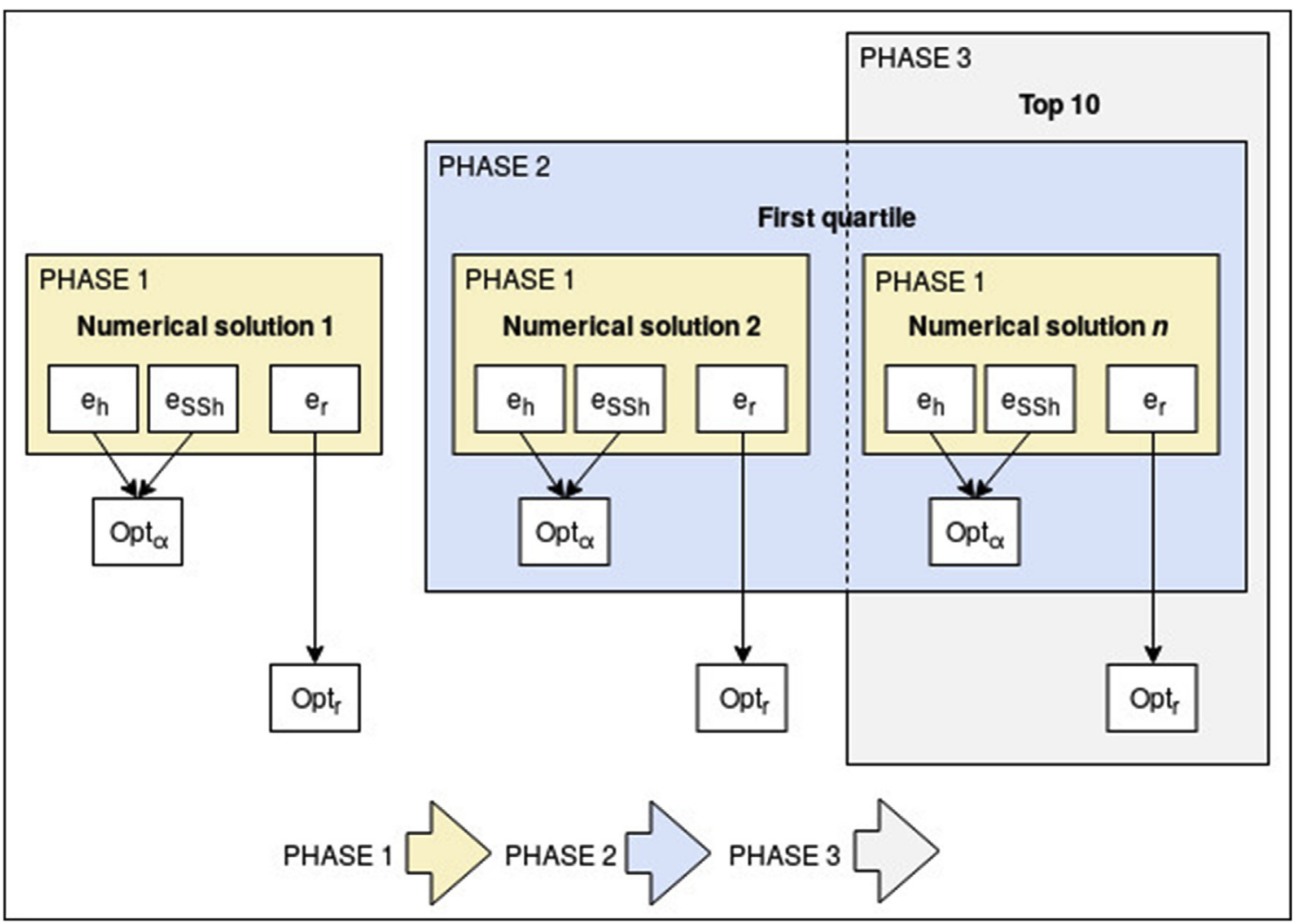

Fig. 2. Flow-chart of the double standard optimization paradigm.

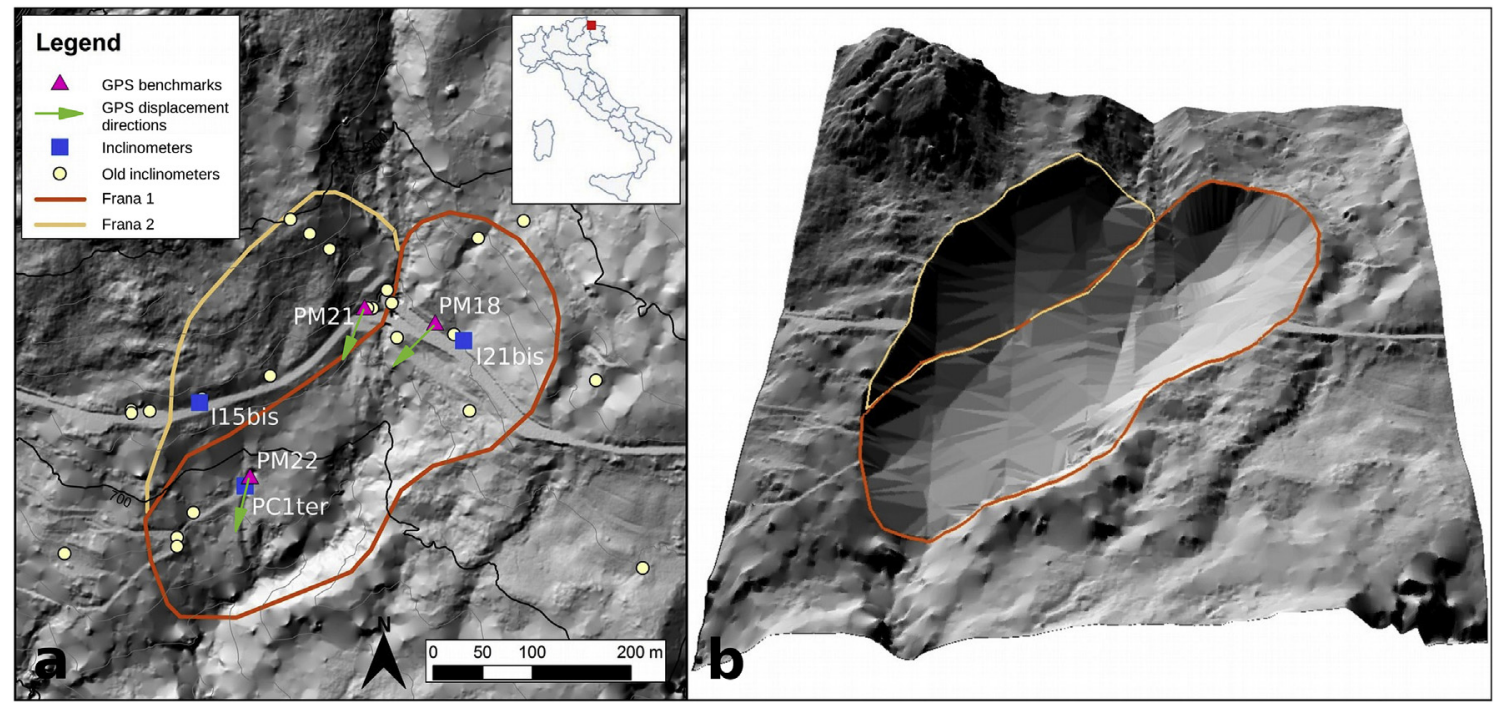

Fig. 3. (a) Representation of the study area, the monitoring system and the displacement directions of the GNSS benchmarks. (b) The 3D reconstruction of the slip surface.

in real-time along the slip surface by means of in-place inclinometers and rainfall events exists and there are no evidences about shallower superimposed instabilities above the very distinct slip surface that is located at 23-24 m below ground surface. Besides the cumulated displacements recorded by the inclinometers are coherent with GNSS periodic surveys (Fig. 4) and the average slope angle of the landslide is less than $20^{\circ}$ so the geometry is not favorable to rainfall induced shallow instabilities. Future work will investigate internal erosion as main driving force for the landslide (Nord and Esteves, 2010; Cui et al., 2019), focusing on the effect induced by the presence of the Rio Verde stream and/or the springs that are located near the crown of Frana 1 (Lan et al., 2013; Nunes Lourenço et al., 2015).

At date a monitoring system consisting of 3 GNSS benchmarks (Table 3 ) and 3 inclinometers (Table 4 ) is following the landslide displacements ( $n=3$ and $k=3$ are respectively the number of the GNSS benchmarks and of the inclinometers considered in the case study). The displacements monitored are expressed in polar coordinates in Table 5 and the mutual ratios of the GNSS benchmark displacements are reported 

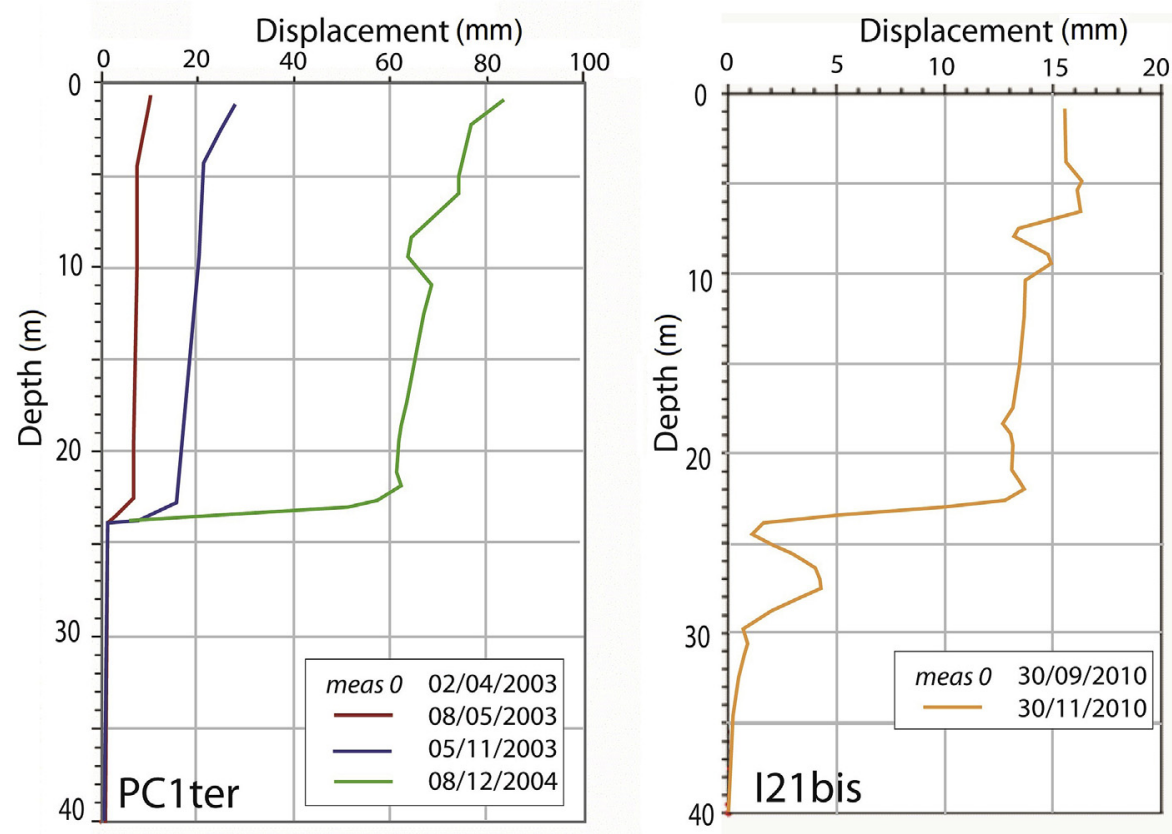

Fig. 4. Inclinometer profiles of two monitored points: PC1ter and I21bis.

in Table 6. The average velocity is $1.0-1.5 \mathrm{~cm}$ /year in the western side and $3-3.5 \mathrm{~cm} /$ year in the eastern area. The water table, measured in the inclinometric boreholes, does not ever reach the slip surface (SS), even during intense rainy events, so for this specific landslide we can discard the instability effect induced by pore water pressure variation (\#2). The measures in the two inclinometers of Frana 1 show a distinct slip surface while in Frana 2 the displacements are distributed along the whole landslide body (Zabuski et al., 2017). The numerical model was therefore designed with two material composing Frana 1, one for the actual landslide body and the other one for the slip surface, while Frana 2 was composed by a single material for both, landslide body and slip surface (Sinigardi et al., 2015).

The geometry of the slip surface has been reconstructed using as control points the location of the slip surface recorded in 20 inclinometers that have operated in the area during 2002-2010 and the contour of the landslides reconstructed on the base of geo-morphological evidence (Fig. 3). The influence of the uncertainty linked with the geometry of the slip surface (\#1) may be thus assessed as negligible. A $1 \mathrm{~m}$ cell helicopter borne LiDAR Digital Terrain Model (DTM) of the area is available. The DTM has been resampled into a $10-m$ grid for the three-

Table 3

Geographical coordinates of the benchmarks, reference system EPSG 102092, elipsoid WGS84.

\begin{tabular}{lllll}
\hline Point & Date & Lat North (N) & Lon East (E) & Elevation a.s.l. (H) \\
\hline \multirow{2}{*}{ PM18 } & 2012 & $2344316.793 \mathrm{~m}$ & $5140763.890 \mathrm{~m}$ & $789 \mathrm{~m}$ \\
& 2014 & $2344316.788 \mathrm{~m}$ & $5140763.800 \mathrm{~m}$ & $789 \mathrm{~m}$ \\
PM21 & 2012 & $2344263.817 \mathrm{~m}$ & $5140777.976 \mathrm{~m}$ & $785 \mathrm{~m}$ \\
& 2014 & $2344263.799 \mathrm{~m}$ & $5140777.938 \mathrm{~m}$ & $785 \mathrm{~m}$ \\
PM22 & 2012 & $2344130.705 \mathrm{~m}$ & $5140602.471 \mathrm{~m}$ & $738 \mathrm{~m}$ \\
& 2014 & $2344130.700 \mathrm{~m}$ & $5140602.389 \mathrm{~m}$ & $738 \mathrm{~m}$ \\
\hline
\end{tabular}

Table 5

Displacements monitored $\left(\alpha_{\mathrm{m}}, \alpha_{\mathrm{SSm}}, \gamma_{\mathrm{m}}\right)$ between 2012 and 2014 and expressed in polar coordinates referred to the zenit $(\mathrm{Z})$ and the geographic north $(\mathrm{N})$

\begin{tabular}{llll}
\hline Type of displacement & Point & Displacement (rad, rad) & \\
\cline { 3 - 4 } & & Horizontal angle $\left(\alpha_{m}, \alpha_{S S m}\right)$ & Vertical angle $\left(\gamma_{m}\right)$ \\
\hline \multirow{2}{*}{ Superficial } & PM18 & 3.85 & 1.59 \\
& PM21 & 2.81 & 1.08 \\
\multirow{4}{*}{ Deep } & PM22 & 3.00 & 1.39 \\
& I21bis & 3.93 & - \\
& PC1 ter & 3.54 & - \\
\hline
\end{tabular}

dimensional reconstruction of the slope surface to reduce the computational time using the local weighted average. According to Vianello et al. (2009) the average resampling method seems to be the most respectful way to reproduce the slope when resampling LiDAR data.

The mesh of the three-dimensional model is composed by 20014 hexahedral elements (Fig. 5). The DSS presented in this paper is independent of the rheology selected for the analysis and from the number of the parameters required. For the example application a Mohr Coulomb failure criteria has been chosen. This does not mean that other rheologies or other soil parameters might have an influence in the proper reconstruction of the process. Mohr Coulomb has been used for straightforwardness and simplicity and to allow an easier readability of the results.

Values derived from laboratory tests have been assigned to the unit weight and the elastic parameters. The four Mohr Coulomb parameters, friction angle $(\varphi)$ and cohesion (c) respectively for the Frana 1 landslide body and the Frana 1 slip surface (Table 7) have been permuted to generate 3024 admissible numerical solutions for the problem from which to select the best-fitting ones. It was decided to use two units of

Table 4

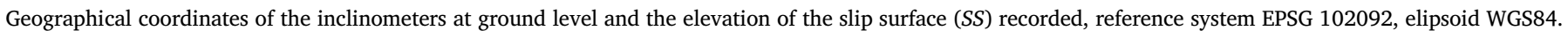

\begin{tabular}{|c|c|c|c|c|c|}
\hline Point & Date & Lat North (N) & Lon East (E) & Elevation a.s.l. (H) & Elevation a.s.l. of SS \\
\hline I21bis & 2010 & $2344361.299 \mathrm{~m}$ & $5140673.531 \mathrm{~m}$ & $739 \mathrm{~m}$ & $716 \mathrm{~m}$ \\
\hline PC1ter & 2012 & $2344140.216 \mathrm{~m}$ & $5140527.136 \mathrm{~m}$ & $690 \mathrm{~m}$ & $666 \mathrm{~m}$ \\
\hline I15bis & 2012 & $2344094.385 \mathrm{~m}$ & $5140611.060 \mathrm{~m}$ & $729 \mathrm{~m}$ & $712 \mathrm{~m}$ \\
\hline
\end{tabular}


Table 6

Matrix of the ratios between entities of monitored displacements.

\begin{tabular}{llll}
\hline Displacements & PM18 & PM21 & PM22 \\
\hline PM18 & 1 & 0.50 & 0.95 \\
PM21 & 1.99 & 1 & 1.89 \\
PM22 & 1.05 & 0.53 & 1 \\
\hline
\end{tabular}

measures intervals for the analysis both for cohesion and friction angle as it seems to us a good balance between number of possible permutation and geotechnical meaning of the quantity. Besides, since the basic idea of the method was to "go blind", a wide range of soil parameters was used considering as central points the average of the geotechnical tests that were performed on the soil samples and then expanding them until excessive displacements (no convergence) or no movements were observed. The use the Point Estimate Method was also considered but since back analysis often starts with very little knowledge of the material involved, and back analysis is our benchmark, it was decided to use this very simple approach.

Mohr Coulomb values of Frana 2 have been deemed to be far less influential and have been kept constant in this analysis to reduce the computational effort. In any case, the mutual influence of Frana 2 and Frana 1 has been taken into consideration by the monitored displacements at PM21 and I15bis (Fig. 3a).

\section{Results and discussion}

The double single-objective optimization problem solved by the core system algorithm is based on an empirical approach that compares monitored and modelled quantities.

The close relation to the physical behavior of the soil mass represented by the monitoring data guarantees a high reliability of the solution proposed.

Unlike the most used method to determine the soil parameters of landslides which is exclusively based on the investigator expertise, the semi-automated DSS is validated by the operator which supervises the automated process and the final solution. The presence of an operator contribution in the final result does not undermine the utility of the automatic search activity achieved by the system, rather, it reduces the potential errors linked with the purely operator dependent procedure.

Considering the context of the case study proposed, the optimization problem can be resumed mathematically as: given $h: A \subseteq R^{2} \rightarrow R, q: B \subseteq$ $A \rightarrow R$ and $e_{h_{0}}, e_{S S h_{0}}, e_{r_{0}}, O p t_{\alpha}, O p t_{r} \in R$ where $h\left(e_{h}, e_{S S h}\right)=O p t_{\alpha}, q\left(e_{r}\right)=$ $O p t_{r}$ find $e_{h_{0}}, e_{S S h_{0}}, e_{r_{0}} / h\left(e_{h_{0}}, e_{S S h_{0}}\right) \& q\left(e_{r_{0}}\right)$ are absolute minimum.

The search algorithm is focused on the $h$ and $q$ function minimization.

The dependencies $f\left(e_{h}\right)=O p t_{\alpha}, f\left(e_{S S h}\right)=O p t_{\alpha}$ and $f\left(e_{r}\right)=O p t_{\alpha}$ are described in Fig. 6a ( $f$ is a generic function). The graph compares in the searching space of the modelled solutions the $\mathrm{Opt}_{\alpha}$ value and the divergences associated. In particular Fig. 6a describes the space of the firststage of the optimization analysis where from 1939 numerical solutions $(S)$ represented, only 485 solutions was used in the second-stage. The 485
Table 7

Input soil parameters permutation for modelled solutions construction and relative values used in the case study presented.

\begin{tabular}{ll}
\hline Soil parameters & Case study input values \\
\hline$\varphi\left({ }^{\circ}\right)$ & $16,18,20,22,24,26,28,30$ \\
$c(\mathrm{kPa})$ & $12,14,16,18,20,22,24,26,28$ \\
$\varphi_{S S}\left({ }^{\circ}\right)$ & $12,14,16,18,20,22$ \\
$c_{S S}(\mathrm{kPa})$ & $8,10,12,14,16,18,20$ \\
\hline
\end{tabular}

solutions, included in the range values $0.06<O p t_{\alpha}<0.08$, correspond to the first quartile of total solutions.

It is noticeable the trend of the $f\left(e_{r}\right)$ curve in Fig. 6a. The numerical solutions that minimized the $O p t_{\alpha}$ values, and thus the horizontal divergences of the displacements $\left(e_{\alpha}\right.$ and $\left.e_{S S h}\right)$, minimized also the divergences of the ratios $\left(e_{r}\right)$ in the first quartile, whereas they are independent from $O p t_{\alpha}$ in the remaining solutions. Therefore, the minimization of $e_{r}$ (by function $q$ ), in which the second-stage of the optimization procedure is focused, starts from the first-stage minimizing $e_{h}$ and $e_{S S h}$ (by function $h$ ). Consequently, the $h$ and $q$ minimization order has been selected to increase the efficiency in optimization.

Moreover, in Fig. 6a it is noticeable the similar trends of $f\left(e_{h}\right)$ and $f\left(e_{S S h}\right)$ to support the assumption focused on the minimization of the variables $e_{h}$ and $e_{S S h}$ through the single $O p t_{\alpha}$.

The resizing of the LiDAR resolution in a less detailed mesh increase the spatial significance of the punctual surveys. Each geo-localized point monitored has been spatially coupled with the relative cell of the numerical mesh, thus the slope failure movement of the Frana 1 is described by 6 cells representing a significant volume according to the thickness of the cells.

These assumptions are adequate to the object of the study since the model framework is empirical and aimed to develop a DSS.

Few monitored points and a simple monitoring system allow making the model easy to apply. In particular, 3 superficial and 3 deep monitored points represent the minimal requirement to apply the model proposed. This means on the other hand that the model could be updated easily if and when more monitoring points will be available.

The errors induced by this strong simplification are in any case more data supported with respect to a classical operator-dependent backanalysis procedure. To guarantee a physical significance to the model proposed, it is fundamental to consider the optimum criteria based on the divergences $\left(e_{h}, e_{S S h}, e_{r}\right)$. It represents a functional relation between the superficial and deep physical phenomena. Moreover, the $r$ variable allows relating punctual assessments to the distributed comprehension of the failure. In particular, it allows considering the influences of the tensions acting on the mass boundaries, reflecting the selected rheology, and taking into consideration the interactions between cells.

Fig. $6 \mathrm{~b}$ shows the density distribution of the FLAC3D ${ }^{\mathrm{TM}}$ modelled solutions. It highlights a peak concentration of the modelled solutions in a limited interval $\left(0.06<O p t_{\alpha}<0.08\right)$ which coincides the first quartile of the solutions distribution, whereas in Fig. 7 the 10 solutions proposed
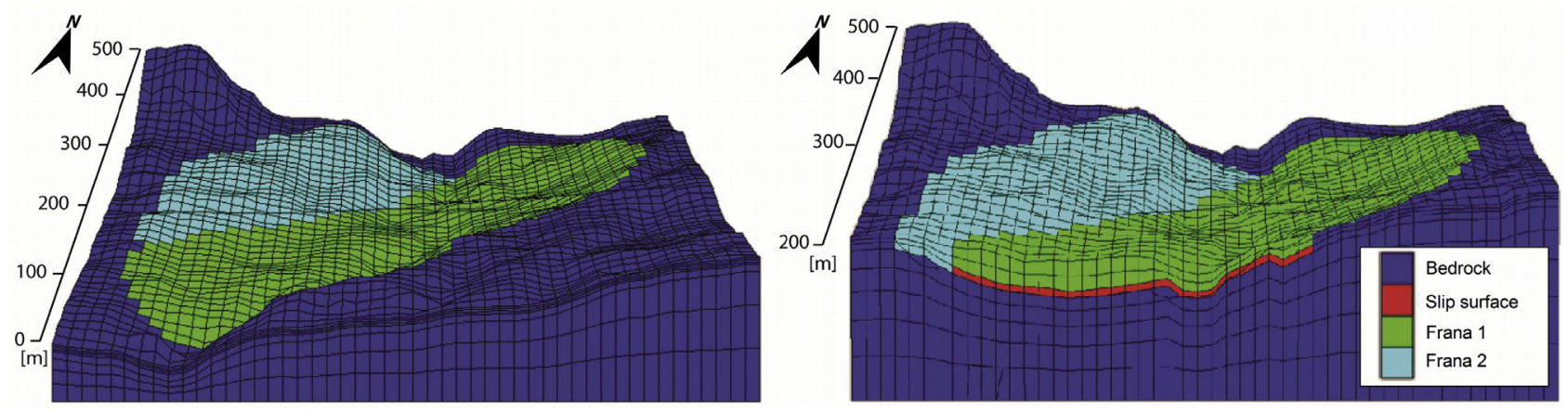

Fig. 5. Mesh calculation of the three-dimensional model of the study area. 


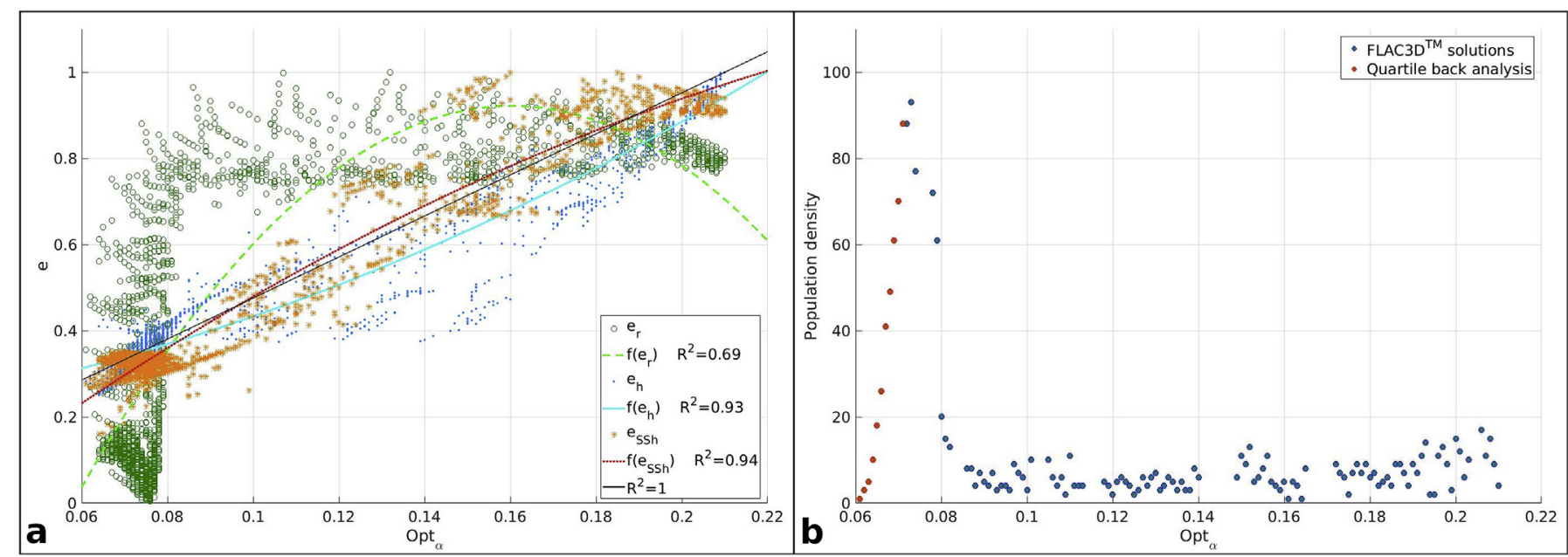

Fig. 6. (a) Mathematical optimization problem description. The green, blue and red curves represent respectively the $f\left(e_{r}\right), f\left(e_{h}\right), f\left(e_{S S h}\right)$ functions. (b) Density distribution of the FLAC3D ${ }^{\mathrm{TM}}$ solutions respect to the optimum opt $_{\alpha}$ focused on the domain defined by the first-stage analysis equal to the first quartile of numerical solutions.

by the DSS are presented (Table 8). This distribution is intrinsic to the case study and influenced by the assumptions adopted.

The first 10 best solutions selected by the search model are characterized by identical values of soil parameters for the slip surface. This means that using the values of $16^{\circ}$ for friction angle and $8 \mathrm{kPa}$ of cohesion for this landslide could lead to a dependable model on which it would be possible to base the design of countermeasure works. As it is shown in Fig. 8 the green dots representing $\varphi_{S S}=16^{\circ}$ distributed in a large portion of the solution space but some of them reach the lowest values of $e_{r}$, while values of $\varphi_{S S}<16^{\circ}$ tend to increase $e_{r}$. Therefore, some solutions with $\varphi_{S S}$ $=16^{\circ}$ create a local convexity, thus a minimum in the divergences space with respect to $e_{r}$. On the other hand, solutions analyzed with respect to $\varphi$ (Fig. 9) show a large variation of possible values near the minimum of $e_{r}$ and for $0<e_{r}<0.2$ all the range of possible $\varphi$ are present. However, high values of $\varphi$ are a little more proximal to the minimum of $e_{S S h}$ and $e_{h}$ than the others. Thus, the sets of soil parameters associated to the Frana 1 of Table 8 show larger variability but they comprehend values that characterize significantly more resistant materials, especially with high values of friction angle with respect to the slip surface.

The 10 solutions have been inspected by an operator, they do not differ so much and this means that the parameters of the slip surface are

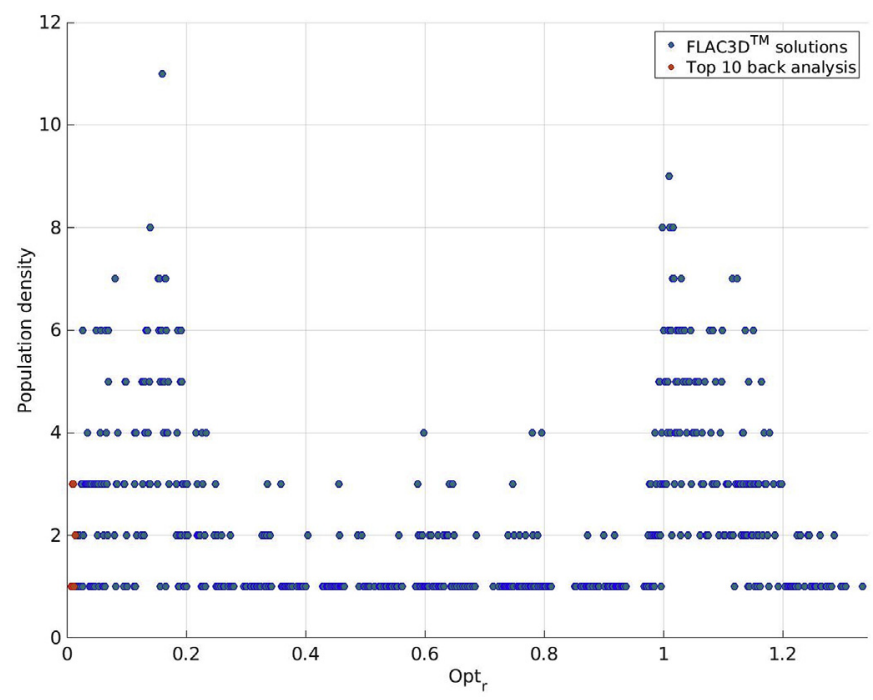

Fig. 7. Density distribution of the FLAC $3 D^{\mathrm{TM}}$ solutions respect to the optimum $\mathrm{Opt}_{\mathrm{r}}$ focused on the top 10 solutions.
Table 8

Soil parameters of top 10 backward analysis solutions.

\begin{tabular}{lllll}
\hline$\#$ & $\varphi\left(^{\circ}\right)$ & $c(\mathrm{kPa})$ & $\varphi_{S S}\left(^{\circ}\right)$ & $c_{S S}(\mathrm{kPa})$ \\
\hline 1 & 26 & 28 & 16 & 8 \\
2 & 28 & 20 & 16 & 8 \\
3 & 28 & 22 & 16 & 8 \\
4 & 30 & 14 & 16 & 8 \\
5 & 28 & 24 & 16 & 8 \\
6 & 30 & 16 & 16 & 8 \\
7 & 28 & 26 & 16 & 8 \\
8 & 30 & 18 & 16 & 8 \\
9 & 28 & 28 & 16 & 8 \\
10 & 30 & 20 & 16 & 8 \\
\hline
\end{tabular}

the factor that most influence the kinematic of the models, as expected. The operator, anyway, selected the solution number 2 that shows a displacement pattern with somewhat higher distributed displacements near the toe of Frana 1. The fact that, in this example, the solutions selected by the DSS are similar, does not hinder the utility of the second phase operator decision. In fact, in other case studies the differences may be more pronounced or that local minima may be detected by the procedure. Furthermore we believe that a human control phase is always needed, especially when monitoring data coverage on the landslide is not well distributed and the number of the monitoring points is not that much representative of the landslide magnitude.

In fact, it is epistemologically impossible to produce a method which is univocally right because of the discrete nature of the optimization process with respect to a large continuous object such a landslide. For this reason we developed the DSS to search to near-optimal solutions that are most coherent with the available, again discrete, monitoring data. But, how "near" are the solutions proposed by the DSS? While we can estimate the accuracy well in the proximity of the monitoring points with the Opt index, the landslide covers much more area. For this reason we think it is important to keep and maintain "expert knowledge" as last step of the procedure to include all the qualitative elements that may not be included in a quantitative assessment, to include in a synthetical solution all the phenomenological entities that characterize a landslide displacement pattern. That is why we highlight the expression "support the operator" or "Decision Support System", the final decision is still depending on the operator. Anyway, we can assume that the accuracy of the results selected by the operator after the DSS procedure is comparable with the accuracy of the solution selected by the trial-and-error procedure, which is too qualitative. For this reason we can compare the two methodologies in terms of 


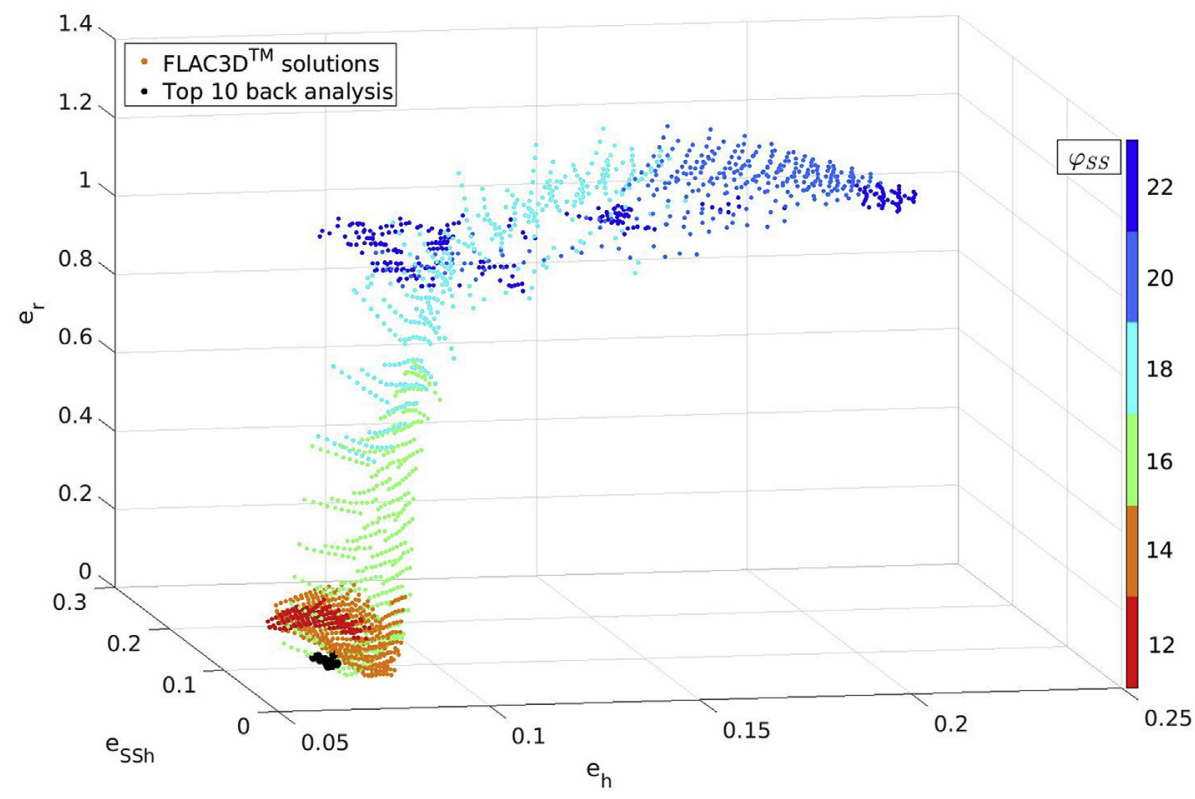

Fig. 8. The three-dimensional distribution of the solutions according to the divergences and graduated according to the friction angle of the SS of Frana 1 .

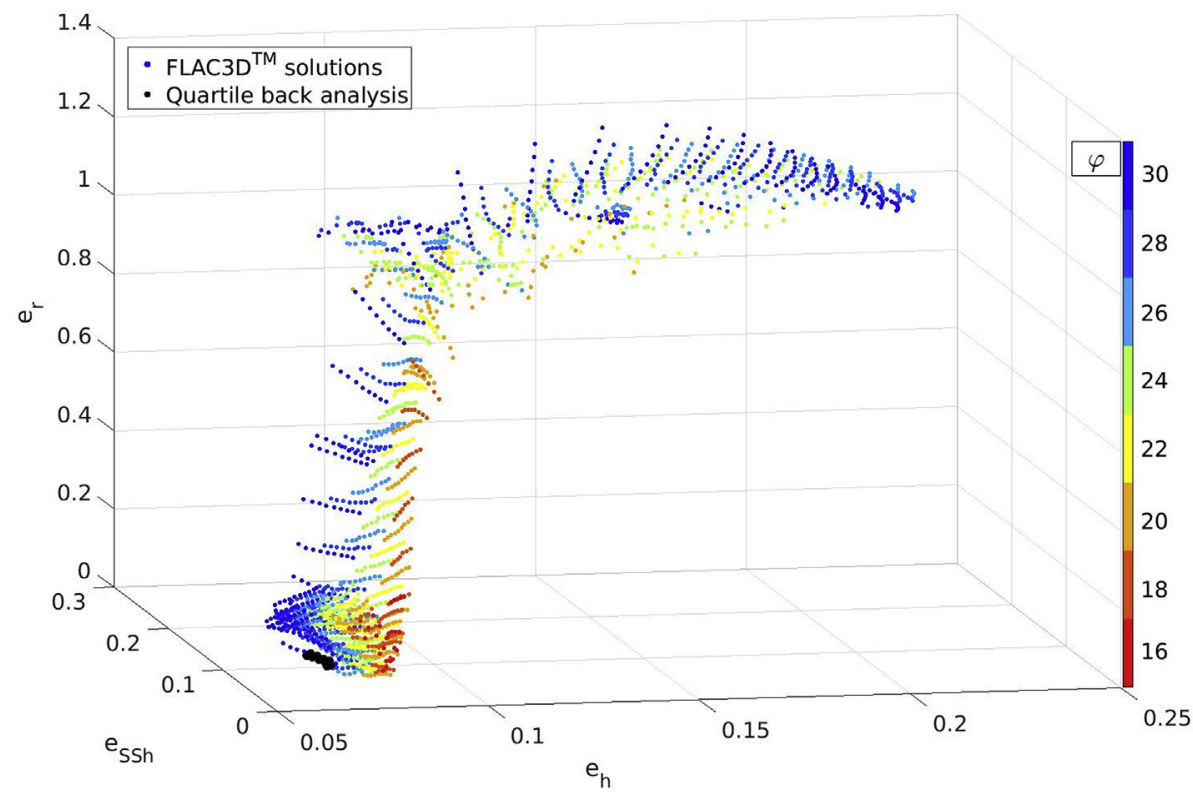

Fig. 9. The three-dimensional distribution of the solutions according to the divergences and graduated according to the friction angle of the Frana 1 body.

accuracy, efficiency, bias and time-consuming.

The comparison between the model, which has been calibrated by an independent operator through a basic trial-and-error procedure, and the DSS solutions is of interest because it gives some indications about the operator biases. The operator in a blind procedure selected the values of $14^{\circ}$ and $10 \mathrm{kPa}$ for the friction angle and cohesion of the slip surface and $24^{\circ}$ and $18 \mathrm{kPa}$ for the friction angle and cohesion of the landslide.

The first thing that appears in Fig. 10 showing the comparison of cumulated displacements of the three solutions, is that the operator solution shows the highest values of displacements. It is essentially linked to the $2^{\circ}$ difference between values of friction angle for the slip surface. This means that the operator suffers a bias that requires the entity of superficial displacements on which to calibrate the model to be less subdue and more evident, even though the entity of superficial displacements should not be accounted for since the model is calibrated on the relative displacements measured in the GNSS benchmarks. This effect could be called graphical bias. Using an operator-independent procedure it is possible to motivate the selection of the design soil parameters following a straightforward procedure discarding the errors associated with the practitioners' biases.

Therefore, how wrong is the operator? What may console technicians and practitioners that have built several structural mitigation measures using back-analysis is that the operator is wrong, but not excessively (Fig. 11). The solution of the operator lies in the first quartile for the first phase of the search algorithm and ranking 260 with respect of $O p t_{r}$. Its $O p t_{r}$ value is 0.0708 with a minimum of 0.0610 and a maximum of 0.0730 for the first quartile. Moreover, the bias shown by the operator in this case tend to be conservative, thus the eventual countermeasure work designed based on the trial-and-error procedure would have been overdimensioned, thus more expensive, but not unsafe.

Summarizing, the advantages of this method are: 

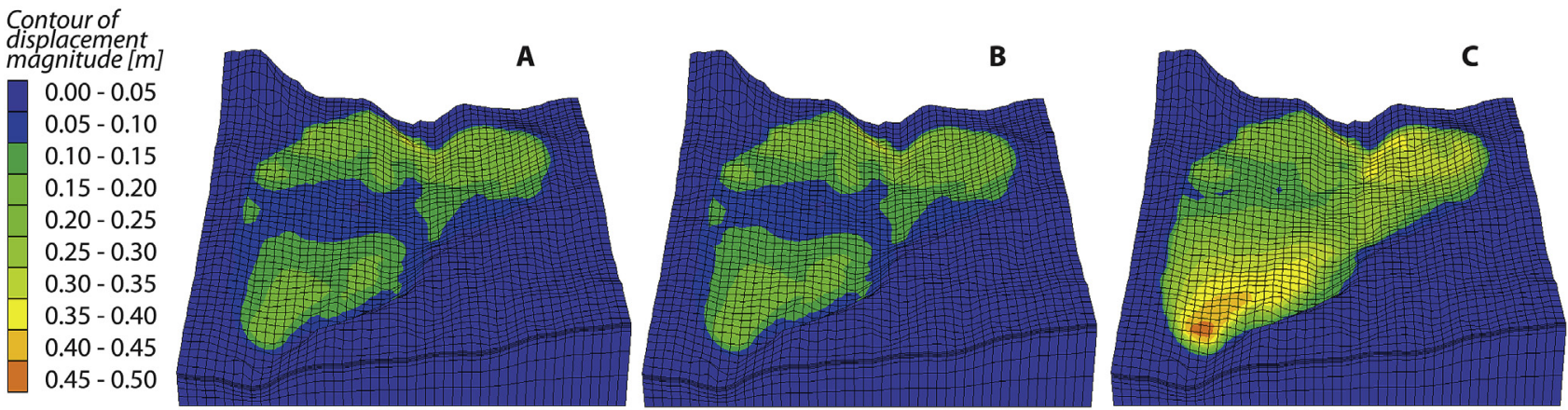

Fig. 10. Contour displacement maps for (A) best fit solution for the algorithm; (B) best fit solution selected by the operator among the best 10 selected by the algorithm; (C) best fit solution selected by an operator in a trial-and-error procedure.

(i) it removes most of the operator biases. It allows to rely on a datadriven straightforward procedure rather than only on a vague "it seems right to me" that it usually the epistemological base for any back-analysis result. The results that may arise from this type of analysis are more defendable and solid both at the design stage as in case of legal disputes;

(ii) in cases like the one here presented it can support the reduction of construction costs since it is shown that using operator-dependent back-analysis may lead to oversizing the countermeasure works, with impact also on the landscape and the environment;

(iii) in other condition it may lead to identify local minimum that are unfavourable combination of parameters that could point to nearto-collapse slopes. That is extremely interesting in the optic of reliability analysis.

\section{Conclusions}

A procedure that allows selecting the soil parameters that are more congruent with monitoring data of landslide displacements has been presented. The procedure is (i) straightforward, (ii) scalable and (iii) robust. (i) The DSS does not rely on a stochastic analysis but uses a pool consisting of all the admissible solutions. This, even though on one hand increases the computational effort, on the other allows the operator to analyze the results cloud with more detail and to identify an extract the most important elements that concur in the model slope dynamic. Since we are a presenting a DSS we believe that a procedure that is as transparent as possible may be more useful for the operator to take informed decisions. Moreover, the time required to compute all the solutions is comparable with the time required by an operator to select a solution with a trial-anderror procedure. Besides, with the proposed method results are made available while the operator may work on other projects. Moreover, in a framework were computational times are continuously reducing by the increasing potentialities of PC and even more through cloud computing, the confront between the trialand-error procedure and the proposed method will become by the month more marked.

(ii) The scalability of the procedure means (1) it can handle as many monitoring points as available; (2) the analysis could be refined on the basis of new monitoring data without computing a new pool of admissible solutions.

(iii) The DSS is robust because it is simple. The inputs are merely the locations of the monitoring points and the associated

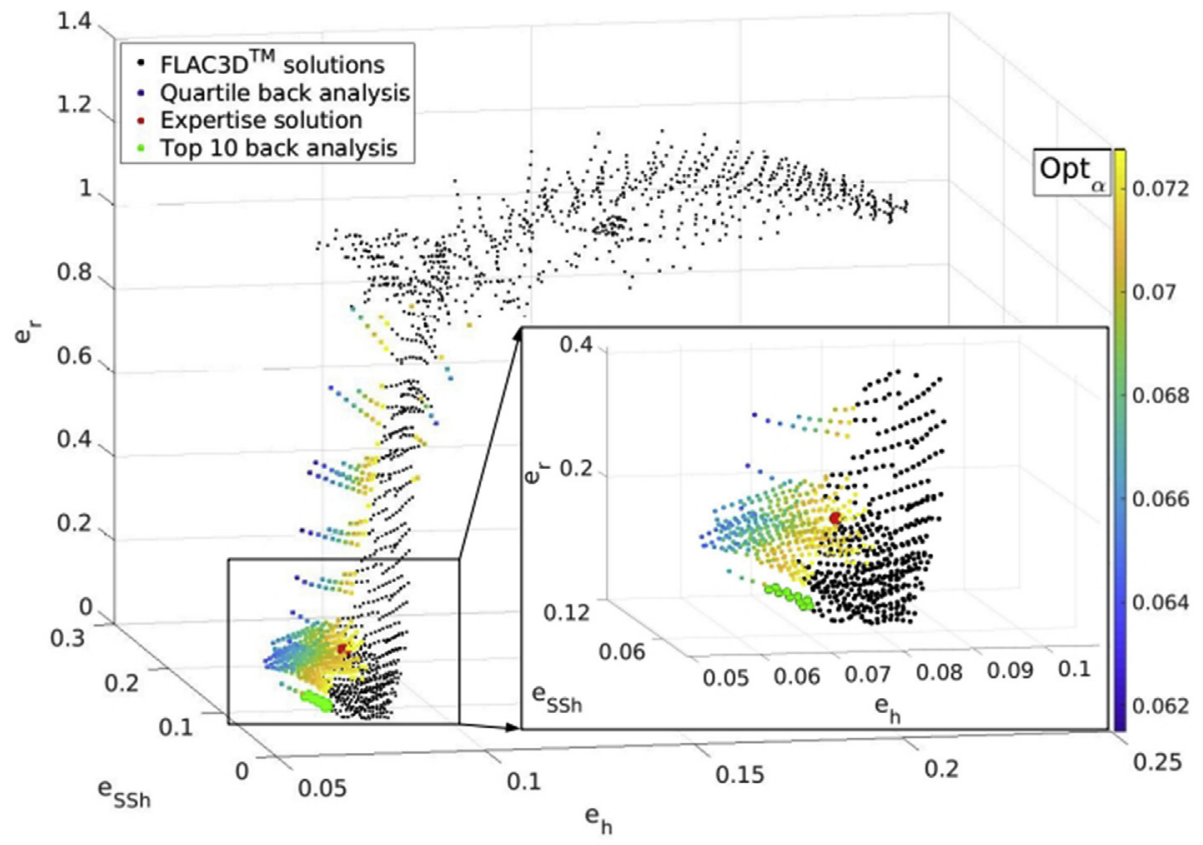

Fig. 11. The three-dimensional distribution of the solutions according to the divergences. 
displacements. No calibration phase is required. It may handle any rheology and it could be implemented with different geotechnical numerical codes.

These three elements make the presented DSS a tool that could be useful for researchers and practitioners.

\section{Declaration of competing interest}

The authors declare that they have no known competing financial interests or personal relationships that could have appeared to influence the work reported in this paper.

\section{Acknowledgements}

GB conceived the experiment, designed the geotechnical model, generated the pool of the numerical solution in FLAC3 $\mathrm{D}^{\mathrm{TM}}$, analyzed monitoring data, was the operator who selected the solutions. GT conceived the optimization strategy, designed and implemented the optimization algorithm, produced the figures. GB and GT wrote the paper. GM implemented the monitoring system and analyzed data. AP and GM revised the paper.

The work was financed by the CNR-IRPI in the context of the SinoItalian Laboratory on Geological and Hydrological Hazards (CUPB96J16001430005) between the National Research Council of Italy (CNR-IRPI) and the Chinese Academy of Sciences (CAS-IMHE).

The DSS code is published and freely available in the GitHub repository https://github.com/CNR-IRPI-Padova/SPS (Titti and Bossi, 2020).

\section{References}

Borgatti, L., Corsini, A., Marcato, G., Ronchetti, F., Zabuski, L., 2008. Appraise the structural mitigation of landslide risk via numerical modelling: a case study from the northern Apennines (Italy). Georisk 2, 141-160. https://doi.org/10.1080/ 17499510802200261.

Cui, Y., Jiang, Y., Guo, C., 2019. Investigation of the initiation of shallow failure in widely graded loose soil slopes considering interstitial flow and surface runoff. Landslides 16, 815-828. https://doi.org/10.1007/s10346-018-01129-9.

Deb, K., 2005. Multi-objective optimization. In: Search Methodologies. Springer, Boston, MA, pp. 273-316 doi: 10.c1007/0-387-28356-0_10.

Deschamps, R., Yankey, G., 2006a. Limitations in the back-analysis of strength from failures. J. Geotech. Geoenviron. Eng. 132, 532-536. http://ascelibrary.org/do i/10.1061/\%28ASCE\%291090-0241\%282006\%29132\%3A4\%28532\%29.

Doherty, J., Lehane, B., 2009. Evaluating soil parameters using numerical optimisation. In: Proceedings of the 17th International Conference on Soil Mechanics and Geotechnical Engineering: the Academia and Prac-Tice of Geotechnical Engineering, pp. 518-521. https://doi.org/10.3233/978-1-60750-031-5-518.

Gioda, G., Sakurai, S., 1987. Back analysis procedures for the interpretation of field measurements in geomechanics. Int. J. Numer. Anal. Methods GeoMech. 11, 555-583. https://doi.org/10.1002/nag.1610110604.

Hasan, S., Najjar, S., 2013. Probabilistic back analysis of failed slopes using bayesian techniques. In: Geo-Congress 2013. American Society of Civil Engineers, Reston, VA, pp. 1013-1022. https://doi.org/10.1061/9780784412787.103.

Jeon, Y.S., Yang, H.S., 2004. Development of A back analysis Algorithm using flac. Int. J. Rock Mech. Min. Sci. 41, 447-453. https://doi.org/10.1016/j.ijrmms.2004.03.081.

Lan, M., Hu, H., Tian, F., Hu, H., 2013. A two-dimensional numerical model coupled with multiple hillslope hydrodynamic processes and its application to subsurface flow simulation. Sci. China Technol. Sci. 56, 2491-2500. https://doi.org/10.1007/ s11431-013-5347-6.

Leroueil, S., Tavenas, F., 1981. Pitfalls of back-analysis. In: Proc., 10th Int. Conf. On Soil Mechanics and Foundation Engineering, vol. 1, pp. 185-190.
Lewis, R.M., Torczon, V., Trosset, M.W., 2000. Direct search methods: then and now. J. Comput. Appl. Math. 124, 191-207. https://doi.org/10.1016/S0377-0427(00) 00423-4.

Marcato, G., Mantovani, M., Pasuto, A., Zabuski, L., Borgatti, L., 2012. Monitoring, numerical modelling and hazard mitigation of the Moscardo landslide (Eastern Italian Alps). Eng. Geol. 95-107. https://doi.org/10.1016/j.enggeo.2011.09.014.

Meier, J., Rudolph, S., Schanz, T., 2009. Effective algorithm for parameter back calculation - geotechnical applications. Bautechnik 86, 86-97. https://doi.org/ 10.1002 /bate. 200910045.

Mitchell, R.J., 1991. Centrifuge modelling as a consulting tool. Can. Geotech. J. 28, 162-167. https://doi.org/10.1139/t91-018.

Nord, G., Esteves, M., 2010. The effect of soil type, meteorological forcing and slope gradient on the simulation of internal erosion processes at the local scale. Hydrol. Process. 24, 1766-1780. https://doi.org/10.1002/hyp.7613.

Nunes Lourenço, S.D., Wang, G.H., Kamai, T., 2015. Processes in model slopes made of mixtures of wettable and water repellent sand: implications for the initiation of debris flows in dry slopes. https://doi.org/10.1016/j.enggeo.2015.06.021.

Olson, D.L., 2008. Multi-criteria decision support. In: Handbook on Decision Support Systems 1 International Handbooks Information System. Springer, Berlin, Heidelberg, pp. 299-314. https://biblioproxy.cnr.it:2280/chapter/10.1007/978-3-540-4 8713-5_15.

Peck, R.B., 1969. Advantages and limitations of the observational method in applied soil mechanics. Geotechnique 19, 171-187. https://doi.org/10.1680/ geot.1969.19.2.171.

Said, G., Mahmoud, A., El Horbaty, E., 2014. A comparative study of meta-heuristic algorithms for solving quadratic assignment problem. Int. J. Adv. Comput. Sci. Appl. 5, 1-6. https://doi.org/10.14569/IJACSA.2014.050101.

Schädler, W., Borgatti, L., Corsini, A., Meier, J., Ronchetti, F., Schanz, T., 2015. Geomechanical assessment of the Corvara earthflow through numerical modelling and inverse analysis. Landslides 12, 495-510. https://doi.org/10.1007/s10346-0140498-5.

Sinigardi, G., Bossi, G., Scuri, A., Marcato, G., Borgatti, L., 2015. Geological and numerical models as a tool to manage landslide risk: the Passo della Morte case study (UD, Italy). Italian J Geosci 34/2015. https://doi.org/10.3301/IJG.2015.35.

Stark, T.D., Hussain, M., 2010. Shear strength in preexisting landslides. J. Geotech. Geoenviron. Eng. 136, 957-962. https://doi.org/10.1061/(ASCE)GT.19435606.0000308.

Stuckman, B., Evans, G., Mollaghasemi, M., 1991. Comparison of global search methods for design optimization using simulation. In: 1991 Winter Simulation Conference Proceedings, pp. 937-944. https://doi.org/10.1109/WSC.1991.185708.

Suits, L.D., Sheahan, T.C., Bareither, C.A., Benson, C.H., Edil, T.B., 2008. Reproducibility of direct shear tests conducted on granular backfill materials. Geotech. Test J. 31, 100878 https://doi.org/10.1520/GTJ100878.

Sun, G., Zheng, H., Huang, Y., Li, C., 2016. Parameter inversion and deformation mechanism of Sanmendong landslide in the Three Gorges Reservoir region under the combined effect of reservoir water level fluctuation and rainfall. Eng. Geol. 205, 133-145. https://doi.org/10.1016/j.enggeo.2015.10.014.

Swoboda, G., Ichikawa, Y., Dong, Q., Zaki, M., 1999. Back analysis of large geotechnical models. Int. J. Numer. Anal. Methods GeoMech. 23, 1455-1472. https://doi.org/ 10.1002/(SICI)1096-9853(199911)23:13<1455::AID-NAG33>3.0.CO;2-C.

Tang, W.H., Stark, T.D., Angulo, M., 1999. Reliability in back analysis of slope failures. Soils Found. 39, 73-80. https://doi.org/10.3208/sandf.39.5\73.

Titti, G., Bossi, G., 2020. Cnr-irpi-padova/sps. Sps v0.1. URL. https://doi.org/10. 5281/zenodo.3601172.

Vianello, A., Cavalli, M., Tarolli, P., 2009. Lidar-derived slopes for headwater channel network analysis. Catena 76, 97-106. https://doi.org/10.1016/ j.catena.2008.09.012

Winker, P., Gilli, M., 2004. Applications of optimization heuristics to estimation and modelling problems. Comput. Stat. Data Anal. 47, 211-223. https://doi.org/ 10.1016/j.csda.2003.11.026.

Li, X.Z., Kong, J.M., Xu, Q., 2006. Deformation and development tendency of shiliushubao landslide by numerical modeling. Wuhan Univ. J. Nat. Sci. 11, 840-846. https://doi.org/10.1007/BF02830174 (in Chinese with English abstract).

Yin, Z.-Y., Jin, Y.-F., Shen, J.S., Hicher, P.-Y., 2018. Optimization tech-niques for identifying soil parameters in geotechnical engineering: comparative study and enhancement. Int. J. Numer. Anal. Methods GeoMech. 42, 70-94. https://doi.org/ 10.1002/nag.2714.

Zabuski, L., Bossi, G., Marcato, G., 2017. Influence of the geometry alteration of the landslide slope on its stability: a case study in the Carnian Alps (Italy). Arch. Hydroeng. Environ. Mech. 64, 101-114. https://doi.org/10.1515/heem-2017-0007.

Zhang, J., Tang Wilson, H., Zhang, L.M., 2010. Efficient probabilistic back-analysis of slope stability model parameters. J. Geotech. Geoenviron. Eng. 136, 99-109. https:// doi.org/10.1061/(ASCE)GT.1943-5606.0000205. 